San Antonio Review • San Antonio Review (Issue 2 | Winter 2019)

\title{
Don’t Wake Me Up, Just Yet
}

\section{Mike James}

Published on: Apr 26, 2019

Updated on: Aug 08, 2020

License: Creative Commons Attribution 4.0 International License (CC-BY 4.0). 
It's the dream where I recite my social security number forwards

have sex. Isn't that a pain? The sex robot is accommodating and hints at numbers I stumble over like a teenager running late for class. I always like hints. They are one of my favorite things after Julie Andrews, long walks, big bands, and dark chocolates (the healthy kind.) Does that sound like the personal ad so many poems are? Oh, well. We are all looking for someone even if it ends up being a cat on the windowsill, taking in every bit of sun a room allows. In this case, those aren't the devil, dismissive pair of cat eyes I'm used to. It's ok, though. I'm not afraid. I was trying to not make this about who isn't in the dream. No such-and-such lurch for this old cowboy. I tripped on my boots and fell and fell. Did I mention, the hallway is empty? A band is playing somewhere.

Mike James has been widely published in magazines, large and small, throughout the country. His thirteen poetry collections include: Jumping Drawbridges in Technicolor (Blue Horse), First-Hand Accounts from Made-Up Places (Stubborn Mule), Crows in the Jukebox (Bottom Dog), My Favorite Houseguest (FutureCycle), and Peddler's Blues (Main Street Rag.) He has served as an associate editor for the Kentucky Review and Autumn House Press, as well as the publisher of the now-defunct Yellow Pepper Press. He makes his home outside Nashville, Tennessee. 